\title{
AWARENESS ON BREAST FEEDING AMONG READYMADE GARMENTS (RMG) WORKING WOMEN IN DHAKA CITY
}

\author{
JANNATARA SHEFA ${ }^{1}$, MOHAMMAD FERDOUS UR RAHAMAN ${ }^{2}$, MITHUN ALAMGIR ${ }^{3}$, MD. ABUL KALAM \\ $\mathrm{AZAD}^{4}$, ROWSAN ARA ${ }^{5}$
}

\begin{abstract}
Back ground: Breast-feeding is the unique source of nutrition that plays an important role in the growth, development and survival of infants. There are lots of readymade garments working (RMG) women in Dhaka city who have poor facilities for their child's breast feeding which is not only a National issue but also an International issue. Objective: To identify the awareness on breast feeding among RMG working women in Dhaka city. Methods: Descriptive Cross Sectional study was conducted among RMG Women in Dhaka City, aged 15-49 years. The study conducted in Readymade Garments factory at Mirpur Police station area in Dhaka city during the period of January 2009 to June 2009. The sample size for the cross sectional study was calculated by using $Z$ test and it was 625. Result: About 94.5\% of the mothers attempted breastfeeding. At 1 month, $71.6 \%$ were still breastfeeding, $49.6 \%$ continued to do so at 2 months, and $29.8 \%$ persisted till 4 months. By 6 months, the breastfeeding prevalence rate fell to $21.1 \%$. The median duration of breastfeeding was 7.0 weeks and the mean duration was 12.7 weeks. The median duration of breastfeeding was shorter than the mean duration as the proportion of mothers who continued breastfeeding was smaller than that of mothers who stopped breastfeeding; and among those who persisted, their average duration were longer. Among the mothers who attempted breastfeeding, the shortest duration was 0.5 weeks, while $21.1 \%$ were still doing so at the end of 6 months. Conclusions: Many women would also find it useful to have more flexible working hours. In some work settings, giving women with young infants extra flexibility in work hours might be a low-cost and effective intervention
\end{abstract}

Keywords: Postnatal care, Reproductive health services, Exclusive breast Feeding, Complimentary food.

\section{Introduction}

Breast-feeding is the unique source of nutrition that plays an important role in the growth, development and survival of infants. The benefits of breast-feeding, especially exclusive breast-feeding, are well established 1,2 .Particularly in poor environments, where early introduction of other milk is of particular concern because of the risk of pathogens contamination and over dilution of milk leading to increased risks of morbidity and under nutrition.

Breast-feeding is promoted internationally as the preferred method of feeding infants up to 4-6 months and continued up to two years with the addition of home cooked food ${ }^{3}, 4$. In Bangladesh, only 14 per cent of infants were exclusively breastfeed up to 3 months. Though a number of studies have been done on breast-feeding in Bangladesh ${ }^{5-8}$, none pointed out factors influencing duration of breast-feeding.

The proportion of Bangladeshi women initiating breast-feeding is relatively low ${ }^{6-8}$. The duration of breastfeeding largely determines how much this form of feeding has a favorable influence on infectious diseases prevention, child development and survival. Working women should be informed through health personnel and communication media, about the benefits of exclusive breastfeeding and about maternity entitlements. Provision of facilities to support breastfeeding in the workplace must also be encouraged so that maternal employment does not hamper breastfeeding. There are lots of RMG working women in Dhaka city who have poor facilities for their

1. Lecturer, Department of Community Medicine, Enam Medical College, Dhaka.

2. Medical Officer, Department of Medicine, Bangabandhu Sheikh Mujib Medical University, Dhaka.

3. Assistant Professor, Department of Community Medicine, Enam Medical College, Dhaka.

4. Associat professor, Department of Medicine, Bangabandhu Sheikh Mujib Medical University, Dhaka.

5. MD (Rheumatology) final part student, Bangabandhu Sheikh Mujib Medical University, Dhaka.

Bangladesh J Medicine 2010; $21: 65-70$ 
child's breast feeding which is not only a National issue but also an International issue

\section{Material and Methods}

Study design

Descriptive Cross Sectional study.

Study place

Mirpur police station area, Dhaka.

Study population

The study was conducted among Readymade Garments Working Women in Dhaka City, aged 15-49 years.

Study period

January- June'2009

Sample size

Sample size of 625 was obtained from the study area

Sampling Technique

Sample size for the cross sectional study was calculated by using $Z$ test

Ethical implication

As the study was conducted in the garment factories, first of all a written permission was taken from the factory authority. Then both verbal and written consent was taken from the respondent RMG working women aged 15-49 years.

Data Collection instrument

A questionnaire was prepared as a research instruments in such a way that the interview could flow as naturally as possible. They were designed according to objectives of the study and were made simple and easily understandable manner. The questionnaire was pre-tested on a small number of respondents at Mirpur, Dhaka similar to the study population to identify and difficulty for understanding by the respondents. Then modified and finalized the questionnaire for data collection.

Data collection technique

Proportionate cluster sampling method was used. Five clusters were identified and one was randomly selected. All the Garments working women relate to our purpose and inclusion criteria in the selected cluster was included in the study.

Data processing and analysis

After completion of data collection data were processed and edited manually to reduce error. Both descriptive and analytical statistics were done by SPSS (11.5 versions)

\section{Results}

This was a cross sectional type of descriptive study. A total of 625 respondents' samples from January to June' 2009 was taken and studied. All data were taken, managed and analyzed. The demographic profile of the mothers is given in Table 7. Of the 625 mothers, the mean age of the mothers was 30 years (range 18-45 years). All the respondents were working. About $94.5 \%$ of the mothers attempted breastfeeding. At 1 month, $71.6 \%$ were still breastfeeding, $49.6 \%$ continued to do so at 2 months, and $29.8 \%$ persisted till 4 months. By 6 months, the breastfeeding prevalence rate fell to $21.1 \%$. The median duration of breastfeeding was 7.0 weeks and the mean duration was 12.7 weeks. The median duration of breastfeeding was shorter than the mean duration as the proportion of mothers who continued breastfeeding was smaller than that of mothers who stopped breastfeeding; and among those who persisted, their average duration were longer. Among the mothers who attempted breastfeeding, the shortest duration was three days, while $21.1 \%$ were still doing so at the end of 6 months. The data showed that exclusive breastfeeding at any time between delivery and 6 months is not a common practice. For most mothers, breastfeeding was combined with supplementary feeds of powdered milk. Univariate analysis showed that ethnicity, age, educational attainment, religion, household income, working status, household living arrangement, total number of children, previous breastfeeding experience, number of babies delivered, length of mother's stay in hospital after delivery, length of baby's stay in hospital after delivery, baby's sex, whether baby had jaundice, perception of breastfeeding, ability to cite benefits of breastfeeding and advice on breastfeeding received from health professionals during pregnancy were factors related to breastfeeding 2 months after delivery. As some of these factors were inter-related, multivariate analysis was performed using continued breastfeeding as a dependent variable. The results of the multivariate analyses for predicting breastfeeding at 2 months are shown in Table 8 . Interaction effects were investigated and were not included in the analyses as they did not result in a significant improvement of the model. The results of the multivariate analyses for predicting breastfeeding at 6 months are shown in Table 9. The inclusion of any interaction term did not result in a significant improvement over the 'main effects' model and hence were not included in the final multivariate model for breastfeeding at 6 months. 
Unlike the earlier model for breastfeeding at 2 months, ethnicity and age ceased to be significant in the current model for predicting continued breastfeeding at 6 months. Instead variables such as baby's sex, whether baby had jaundice and mother's perception of breastfeeding were found to provide significant predictive information about continued breastfeeding at 6 months.

Table-I

Distribution by the respondents' Marriage Age

\begin{tabular}{lc}
\hline Marriage Age & Frequency \\
\hline$<16$ & 88 \\
$>16$ & 494 \\
\hline
\end{tabular}

Table-II

Distribution by the respondents' No. of Children

\begin{tabular}{lc}
\hline No. of Children & Frequency \\
\hline None & 0 \\
One to two & 62 \\
Three & 520 \\
Four & 0 \\
More & 0 \\
\hline
\end{tabular}

Table-III

Distribution by the respondents' Spouse's Education

\begin{tabular}{lc}
\hline Spouse's Education & Frequency \\
\hline Graduate & 3 \\
Under grad & 52 \\
School & 527 \\
\hline
\end{tabular}

Table-IV

Distribution by the respondents' Relationship with Children

\begin{tabular}{lc}
\hline Relationship with Children & Frequency \\
\hline Happy & 400 \\
Satisfactory & 120 \\
Strained & 62 \\
\hline
\end{tabular}

Table-V

Distribution by the respondents' Food Habits: Timings

\begin{tabular}{lc}
\hline Food Habits: Timings & Frequency \\
\hline Regular & 551 \\
Irregular & 21 \\
Misses meals & 10 \\
\hline
\end{tabular}

\section{Table-VI}

Distribution by the respondents' awareness about breast feeding over radio/TV/health workers :

\begin{tabular}{lc}
\hline Awareness about & Frequency \\
breast feeding & \\
\hline Radio & 551 \\
TV & 120 \\
Health workers & 50 \\
\hline
\end{tabular}

TableVII

Demographic profile of respondents $(n=625)$

\begin{tabular}{lcc}
\hline $\begin{array}{l}\text { Demographic } \\
\text { profile }\end{array}$ & $n$ \\
\hline Age group & & \\
19 years and below & 65 & 1.8 \\
20-29 years & 171 & 36.7 \\
30-39 years & 292 & 56.5 \\
40-45 years & 54 & 5.0
\end{tabular}

Religion

$\begin{array}{lcc}\text { Buddhism } & 0 & 0 \\ \text { Islam } & 474 & 29.9 \\ \text { Christianity } & 10 & 17.6 \\ \text { Hinduism } & 98 & 4.6\end{array}$

Education

$\begin{array}{lcc}\text { Primary } & 255 & 40.8 \\ \text { Secondary } & 277 & 44.32 \\ & & \\ \text { Post-secondary } & 38 & 6.08 \\ \text { Illiterate } & 55 & 8.8\end{array}$

Household income

$\begin{array}{lll}\text { Refusal to answer } & 43 & 10.1\end{array}$

Below $2000 \quad 149 \quad 26.6$

2000-3999 $299 \quad 45.8$

4000-5999 $72 \quad 14.6$

$\begin{array}{lll}6000-7999 & 42 & 9.1\end{array}$

$\begin{array}{lll}8000-9999 & 17 & 4.0\end{array}$

$\begin{array}{lll}10000 \text { and over } & 3 & .7\end{array}$ 
Table-XIII

Predictors of continued breastfeeding at 2 months using multivariate stepwise logistic regression analyses

\begin{tabular}{|c|c|c|c|c|}
\hline Variable & $\begin{array}{c}\text { Exponential } \\
\text { (B) }\end{array}$ & $\begin{array}{c}95 \% \text { interval confidence } \\
\text { exponential (B) }\end{array}$ & $\begin{array}{l}\text { B } \\
\text { for }\end{array}$ & $\begin{array}{c}\text { Standard } \\
\text { error }\end{array}$ \\
\hline 20-29 years & 1 & - & - & - \\
\hline 19 years and below & 0.41 & $0.19,0.91$ & $-\overline{8}$ & 0.40 \\
\hline 30-39 years & 1.30 & $1.04,1.61$ & 0.26 & 0.11 \\
\hline $40-45$ years & 1.24 & $0.77,1.99$ & 0.21 & 0.24 \\
\hline Primary & 1 & - & - & - \\
\hline Secondary & 1.86 & $1.37, \quad 2.51$ & 0.62 & 0.15 \\
\hline Post-secondary & 2.90 & $2.05, \quad 4.09$ & 1.06 & 0.18 \\
\hline Buddhism & 0 & - & - & - \\
\hline Christianity & 2.44 & $1.80,3.32$ & 0.89 & 0.16 \\
\hline Islam & 6.69 & $2.69,16.65$ & 1.90 & 0.47 \\
\hline Hinduism & 2.08 & $0.82,5.31$ & 0.73 & 0.48 \\
\hline Breastfed other babies & 1 & - & - & - \\
\hline Did not breastfed other babies & 0.31 & $0.21, \quad 0.48$ & $\overline{-}$ & 0.22 \\
\hline No experience as this is 1 st baby & 0.87 & $0.70, \quad 1.08$ & $0 . \overline{14}$ & 0.11 \\
\hline Not able to cite any benefit of breastfeeding & 1 & - & - & - \\
\hline Able to cite at least 1 benefit & 2.45 & $1.72, \quad 3.50$ & 0.90 & 0.18 \\
\hline Did not receive advice on breastfeeding from & 1 & - & - & - \\
\hline health professionals during pregnancy & 0.78 & $0.64,0.94$ & $\begin{array}{c}- \\
0.25\end{array}$ & 0.10 \\
\hline
\end{tabular}

Received advice on breastfeeding

Cox and Snell $R^{2}=0.19$.

Table-IX

Predictors of continued breastfeeding at 6 months using multivariate stepwise logistic regression analyses

\begin{tabular}{|c|c|c|c|c|}
\hline Variable & $\begin{array}{l}\text { Exponential } \\
\text { (B) }\end{array}$ & $\begin{array}{c}95 \% \text { interval confidence } \\
\text { exponential (B) }\end{array}$ & $\begin{array}{c}\text { B } \\
\text { for }\end{array}$ & $\begin{array}{c}\text { Standard } \\
\text { error }\end{array}$ \\
\hline Primary & 1 & - & - & - \\
\hline Secondary & 1.54 & $1.02,2.34$ & 0.43 & 0.21 \\
\hline Post-secondary & 2.83 & $1.79,4.49$ & 1.04 & 0.24 \\
\hline Buddhism & 0 & - & - & - \\
\hline Christianity & 2.60 & $1.80,3.75$ & 0.96 & 0.19 \\
\hline Islam & 2.39 & $1.68,3.41$ & 0.87 & 0.18 \\
\hline Hinduism & 1.45 & $0.79,2.65$ & 0.37 & 0.31 \\
\hline Breastfed other babies & 1 & - & - & - \\
\hline Did not breastfed other babies & 0.26 & $0.13, \quad 0.54$ & $\begin{array}{c}- \\
1.34\end{array}$ & 0.37 \\
\hline No experience as this is 1 st baby & 0.75 & $0.58, \quad 0.95$ & $\begin{array}{c}- \\
0.29\end{array}$ & 0.13 \\
\hline Female baby & 1 & - & - & - \\
\hline Male baby & 0.78 & $0.62, \quad 0.98$ & $\begin{array}{c}- \\
0.26\end{array}$ & 0.12 \\
\hline Jaundice & 1 & - & - & - \\
\hline No jaundice & 0.74 & $0.57,0.95$ & $\begin{array}{c}- \\
0.30\end{array}$ & 0.13 \\
\hline $\begin{array}{l}\text { Bottle feeding or combination of } \\
\text { breastfeeding and bottle feeding deemed as } \\
\text { best feeding method }\end{array}$ & 1 & - & - & - \\
\hline Breastfeeding deemed as best feeding method & 3.18 & $1.74,5.82$ & 1.16 & 0.31 \\
\hline Not able to cite any benefit of breastfeeding & 1 & - & - & - \\
\hline $\begin{array}{l}\text { Able to cite at least } 1 \text { benefit } \\
\text { Did not receive advice on breastfeeding }\end{array}$ & 1.74 & $1.00,3.00$ & 0.55 & 0.28 \\
\hline from health professionals during pregnancy & 1 & - & - & - \\
\hline Received advice on breastfeeding & 0.68 & $0.53,0.86$ & $\begin{array}{c}- \\
0.39\end{array}$ & 0.12 \\
\hline
\end{tabular}

Cox and Snell $R 2=0.15$. 

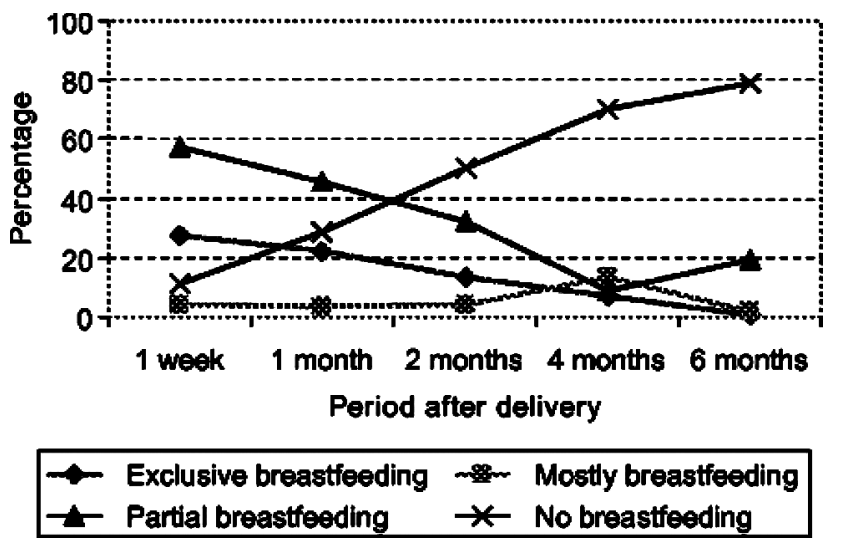

Fig. 1: Type of infant feeding practices adopted by respondents.

\section{Discussion}

It is important continuously to point out that breastfeeding is a woman's right and that society must adapt to this crucial need rather than forcing women to adapt to the sometimes impossible demands placed on them. But the experiences of a breastfeeding promotion project in Panama should caution us not to forget the limitations of such idealistic statements. It was stated in the evaluation of the working women component: “..as long as the activities are principally educational, they are seen as harmless. Trying to get support for enforcement of laws would be substantially more controversial and difficult to obtain".

Often, working women do not perceive it as appropriate to take very young infants to work with them. Due to high costs of housing, poorer women often live far from work, and have to travel on crowded, noisy busses. Constraints of this type probably cannot be overcome by heightened awareness of the importance of exclusive breastfeeding. For example, the Tanzania Food and Nutrition Centre established an on-site day care center in 1979 "to enable TFNC staff to breast feed their children while on duty...and to act as an example to government and organizations." However, a 1988 evaluation noted that no children under the age of 12 months had been brought to the center. There are also situations in which the work place is an unsafe place for an infantand can even contaminate the milk of women who work and breast feed. Crèches at the work place tend to cater to older children and thus would have little impact on breastfeeding. In fact, personnel at day care centers often do not want to accept breast-fed infants unless a bottle is left to feed them in case they get hungry before the mother returns.
Breastfeeding breaks are worth struggling to obtain only when they are sought after by working women. Often women do not work close enough to their babies to find such breaks useful unless they can be combined and used as a way to leave work early. It would be more straightforward in such a case to just allow breastfeeding mothers to work a shorter day.

Many women would also find it useful to have more flexible working hours. In some work settings, giving women with young infants extra flexibility in work hours might be a low-cost and effective intervention. In others it might be nearly impossible for employers to implement. The right to various combinations of fully paid; partially paid and unpaid leaves would probably allow most women to combine optimal breastfeeding with working in the way that best met their economic circumstances and career goals.

\section{The recommendations are:}

1) Maximum flexibility or choice should be allowed to the woman so that the only leave taken before delivery is that which is really needed. (Most health professionals support women's common preference to work up to nearly the date of delivery, except in certain states of ill health.) This allows the bulk of leaves to be taken after delivery.

2) At least four but preferably six months leave should be provided at nearly full pay, to enable women to practice exclusive breastfeeding during this period. Employers should not be asked to pay for this, or if they do, should be given tax credits for it.

3) A small sum of money could be provided to women who wanted to take a longer leave than this, at least for a few months, with no risk of losing their job or their seniority.

4) Flexible and/or shorter working hours for another period of time, should be provided for those women who want it, especially if the total length of the maternity leave is less than four months.

5) Paternity leaves should be encouraged for men to be present at the time of delivery and to assist at home during the time of mother's recovery. In several countries parental leave is offered after the maternity leave and the father is encouraged to spend time at home later in his infant's life. Besides the obvious benefit for mother, father and child, parental leaves would help reduce the bias against hiring women.

6) The study explored the substantial improvement in the selected health parameters including nutritional status, receiving of preventive health 
services or awareness or improvement of socioeconomic condition.

7) The findings relate to the awareness of the Garments workers of deteriorating water supply and sanitation, and personal hygiene was a matter of concern and needs to be addressed in future programs.

8) Information obtained will also be used to design awareness raising and behavior change program by the NGOs and government for the services.

9) Proper utilization of care and services will lead to a better service and thereby decrease maternal mortality and morbidity. This will ultimately lead to build a healthy nation.

\section{References}

1. Ahmed S, Parveen SD, Islam A. Infant feeding practices in rural Bangladesh: policy implication. J Trop Pediatric. 1999; 45: 37-41.

2. American Academy of Pediatrics: Work Group on Breastfeeding Breastfeeding and the use of human milk. Pediatrics. 1997 ;100: 1035-1039.
3. Bangladesh Breastfeeding Foundation $(\mathrm{BBF})$.Situation of breastfeeding in Bangladesh. BBF Research Bull. 2001; 7(2): 4-5.

4. Brown CA, Poag S, Kasprzycki C. Exploring large employers and small employer's knowledge, attitudes, and practices on breastfeeding support in the workplace. J Human Lactation.2001; 17:3946.

5. Pragati C, Vijay GL, Aggarwal OP, Dubey KK. Breast feeding patterns in an urban resettlement colony of Delhi. Indian J Pediatrics. 1998; 65:867-872.

6. Catagay, Nilifur Trade, Gender and Poverty, UNDP, New York. 2001.

7. Fein SB, Roe B. The effect of work status on initiation and duration of breast-feeding. Am J Public Health. 1998; 88:1042-1046.

8. Shanti G, Shireen G, Mittal SK, Verma RK. Sociocultural factors affecting breastfeeding and other infant feeding practices in an urban community. Indian J Pediatrics 1976; 13(2):827-832. 